\title{
Free Prostate-Specific Antigen Provides More Precise Data on Benign Prostate Volume Than Total Prostate-Specific Antigen in Korean Population
}

\author{
Hoon Choi, Jae Young Park, Ji Sung Shim, Jae Heon Kim ${ }^{1}$ Jae Hyun Bae \\ Department of Urology, Korea University Ansan Hospital, Korea University College of Medicine, Ansan; \\ ${ }^{1}$ Department of Urology, Soonchunhyang University Seoul Hospital, Soonchunhyang University College of Medicine, Seoul, Korea
}

\begin{abstract}
Purpose: To investigate the efficacy of total prostate-specific antigen (tPSA) and free prostate-specific antigen (fPSA) for the estimation of prostate volume (PV) in pathologically-proven benign prostatic hyperplasia (BPH) patients.

Methods: From January 2010 to March 2013, 165 Korean men with a PSA less than $10 \mathrm{ng} / \mathrm{mL}$ who were diagnosed without prostate cancer by prostate biopsy were enrolled. Patients were classified into three age groups: $\leq 60,61-70$, and $>70$ years old. The results were organized to estimate and compare the ability of serum IPSA and PPSA to assess the PV.

Results: Enrolled patients had a median age of 63.5 years (44 to 80), a median tPSA of $5.72 \mathrm{ng} / \mathrm{mL}$, a median fPSA of $0.98 \mathrm{ng} / \mathrm{mL}$ and a median PV of $53.68 \mathrm{~mL}$, respectively. Among the associations between tPSA, fPSA, age, and PV, the highest correlation was verified between fPSA and PV $(r=0.377, \mathrm{P}<0.0001)$; the correlation coefficient between $\mathrm{PSA}$ and PV was much lower $(\mathrm{r}=$ $0.262, \mathrm{P}<0.001$ ). All stratified age cohorts showed the same findings. The ROC curves (for PV greater than 30 , 40, and $50 \mathrm{~mL}$ ) showed that PPSA (area under the curve $[\mathrm{AUC}]=0.781,0.718$, and 0.700 ) outperformed tPSA (AUC $=0.657,0.583$, and 0.67 ) in its ability to predict clinically significant PV enlargement.

Conclusion: Both tPSA and fPSA significantly correlated with PV in Korean men, while the correlation efficiency between fPSA and PV was more powerful. fPSA may be a useful tool in making therapeutic decisions and follow-up management in $\mathrm{BPH}$ patients.
\end{abstract}

Keywords: Prostate-specific antigen; Prostatic hyperplasia; Organ volume

\section{INTRODUCTION}

Prostate volume (PV) is powerful predictors of both lower urinary tract symptom (LUTS) and benign prostatic hyperplasia (BPH) as well as the response to medical therapies. Therefore, it is clear that a knowledge of individual PV would be beneficial for everyday management of patients presenting to physicians. This undertaking has some problems, most notably fact that digital rectal examination is relatively inaccurate in measuring the correct prostate size when measured by either transrectal ultrasound (TRUS) or other imaging modalities, such as com- puterized tomography or magnetic resonance imaging. Because imaging modalities accompany financial burden and limited reproducibility, it is reasonable to search for alternative parameters that could be used instead of PV.

Serum prostate-specific antigen (PSA) profiles are easily measured in clinical practice by serum collection. PSA profiles are not only widely used as a screening and testing tool for prostate cancer, but also is of substantial help in the management of men with LUTS and BPH. In other words, PSA, as a parameter for $\mathrm{PV}$, can be used to evaluate the risks of either requiring surgery or developing urinary retention [1].
Corresponding author: Jae Hyun Bae

Department of Urology, Korea University Ansan Hospital, Korea University

College of Medicine, 123 Jeokgeum-ro, Danwon-gu, Ansan 425-707, Korea

Tel: +82-31-412-5114 / Fax: +82-31-412-5194

E-mail: urobae@genetherapy.or.kr

Submitted: June 3, 2013 / Accepted after revision: June 20, 2013
This is an Open Access article distributed under the terms of the Creative Commons Attribution Non-Commercial License (http://creativecommons.org/licenses/by-nc/3.0/) which permits unrestricted non-commercial use, distribution, and reproduction in any medium, provided the original work is properly cited. 
In general, the proportion of free or complexed PSA can be used to improve the cancer specificity of the PSA assay. The percentage of PSA has been established as a useful refinement to the indications for biopsy in men with normal digital rectal examination (DRE) and PSA [2,3].

Considering that both PV and serum PSA increase with age, it seems acceptable to assume some relationship between serum PSA and PV as well.

The aim of our study was to evaluate the diagnostic associations of serum PSA, free PSA, PV, and age among pathologically-proven $\mathrm{BPH}$ patients.

\section{MATERIALS AND METHODS}

From January 2010 to March 2013, we reviewed the medical records of male patients under the approval of a relevant ethics committee. After routine initial baseline studies, these 165 men underwent transrectal prostate biopsies owing to elevated PSA levels of more than $4 \mathrm{ng} / \mathrm{mL}$ or abnormal DRE findings or abnormal hypoechoic lesions on TRUS. Only men with a PSA less than $10 \mathrm{ng} / \mathrm{mL}$ who were pathologically diagnosed without prostate cancer by prostate biopsy were enrolled and rebiopsy patients were excluded. For PSA testing, patients' serum was obtained before prostatic manipulations total PSA and free PSA were evaluated retrospectively. PV was measured with TRUS and PV was defined by measuring the height $(\mathrm{H})$, width $(\mathrm{W})$, and length (L) of the prostate from two selected orthogonal views and calculating the volume $(\mathrm{V})$ as that of the corresponding ellipsoid formula: $\mathrm{V}=0.52 \times \mathrm{W} \times \mathrm{H} \times \mathrm{L}$ [4].

Patients were stratified into three age groups: less than 60, $60-70$, over than 70 . The relationships between total PSA (tPSA), free PSA (fPSA), PV, and age were analyzed using the Pearson correlation coefficient. Receiver operating characteristic (ROC) curves were plotted to estimate and compare the ability of serum tPSA and PPSA to assess the PV. All data were collated using SPSS ver. 12.0 (SPSS Inc., Chicago, IL, USA) and evaluated by the Mann-Whitney U test, logistic regression test, and chi-square test. P-value of less than 0.05 was considered statistically significant.

\section{RESULTS}

Table 1 shows the baseline characteristics of the study population. The group of 165 men with a mean age of $63.53 \pm 8.08$ years had a mean PV of $53.68 \pm 21.93 \mathrm{~mL}$ and mean total and free
Table 1. Patient demographic data

\begin{tabular}{lccccc}
\hline $\begin{array}{c}\text { Age } \\
(\mathrm{yr})\end{array}$ & No. & $\begin{array}{c}\text { Mean age } \\
(\mathrm{yr})\end{array}$ & $\begin{array}{c}\text { Total PSA } \\
(\mathrm{ng} / \mathrm{mL})\end{array}$ & $\begin{array}{c}\text { Free PSA } \\
(\mathrm{ng} / \mathrm{mL})\end{array}$ & $\begin{array}{c}\text { Prostate } \\
\text { volume }(\mathrm{mL})\end{array}$ \\
\hline$<61$ & 56 & $54.48 \pm 4.69$ & $5.66 \pm 2.31$ & $0.83 \pm 0.49$ & $50.48 \pm 20.51$ \\
$61-70$ & 74 & $65.41 \pm 2.74$ & $5.67 \pm 2.18$ & $1.01 \pm 0.54$ & $53.06 \pm 18.77$ \\
$>70$ & 35 & $74.02 \pm 2.69$ & $5.89 \pm 2.43$ & $1.17 \pm 0.65$ & $60.09 \pm 28.70$ \\
Sum & 165 & $63.53 \pm 8.08$ & $5.72 \pm 2.26$ & $0.98 \pm 0.56$ & $53.68 \pm 21.93$ \\
\hline
\end{tabular}

Values are presented as mean \pm standard deviation.

PSA, prostate-specific antigen.

PSA of $5.72 \pm 2.26$ and $0.98 \pm 0.56 \mathrm{ng} / \mathrm{mL}$.

Among relationships between $\mathrm{PSA}$, fPSA, age, and PV, the highest correlation was found between fPSA and PV $(r=0.377$, $\mathrm{P}<0.0001$ ); the correlation coefficient between TPSA and PV was much lower $(r=0.262, P<0.001)$. The results indicated that the PV was remarkably correlated with age and total and free PSA.

The correlation was found in all the cohort group: correlation coefficient 0.198 in less than 61 years old group, 0.403 in 61 to 70 years old group, 0.447 in over than 70 years old group. ROC curves were used to investigate which of PPSA and PSA had a better predictive value for assessing prostate enlargement. Fig. 1 shows ROC curves for prediction of PV (30, 40, and $50 \mathrm{~mL})$ using serum PSA and PPSA.

Area under the curves (AUCs) which revealed that fPSA had reasonable diagnostic power for all stratified age cohorts and showed simillar findings. The ROC curves (for PV greater than 30,40 , and $50 \mathrm{~mL}$ ) showed that PPSA (AUC $=0.781,0.718$, and 0.700 ) outperformed tPSA (AUC $=0.657,0.583$, and 0.634 ) in its ability to predict clinically significant $\mathrm{PV}$ enlargement. These superiorities in all ages were statistically significant.

\section{DISCUSSION}

$\mathrm{PV}$ is perhaps the most extensively studied risk factor for BPH progression. Men with a PV of $\geq 30 \mathrm{~mL}$ are more likely to have moderate-to-severe symptoms (3.5-fold increase), decreased flow rates (2.5-fold increase), and AUR (three- to four-fold increase) than are men with a PV $<30 \mathrm{~mL}$ [5]. So, PV information has become more and more important because the PV strongly predict $\mathrm{BPH}$-related morbidity such as acute urinary retention and the necessitate for surgery [6,7].

Generally, the typical method of measuring PV is TRUS [8]. But, TRUS is relatively painful and the equipment is not always available in primary care settings. Moreover, TRUS is also not 

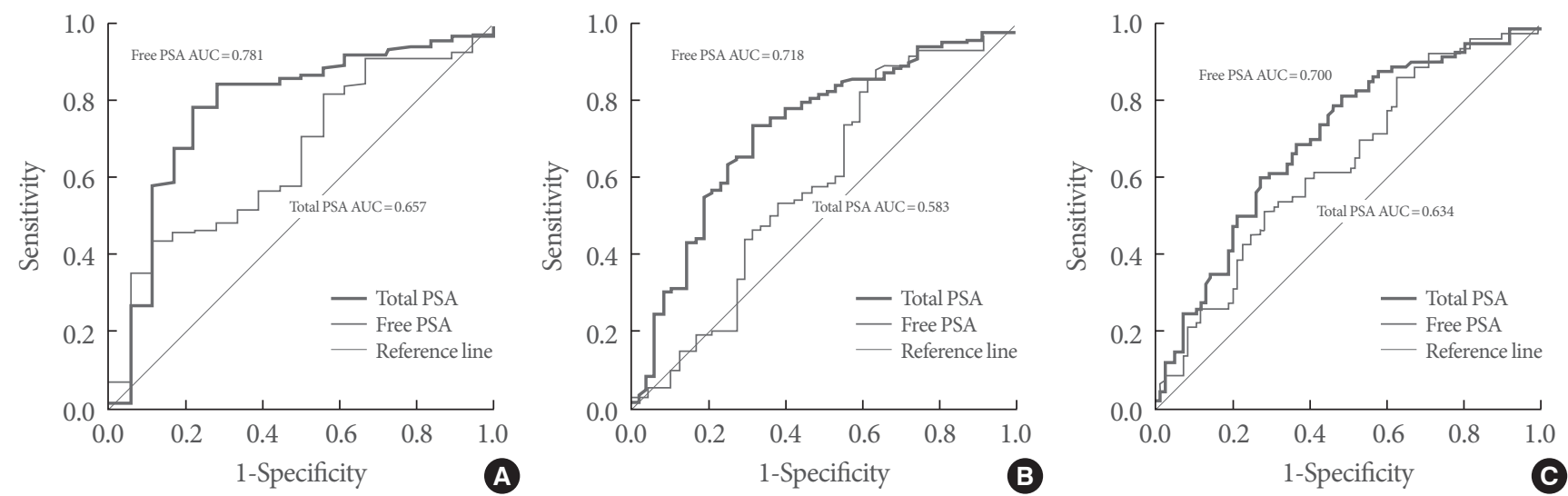

Fig. 1. Receiver operating characteristic (ROC) curves estimating various prostate volumes of total prostate-specific antigen (PSA) and free PSA (fPSA). The areas under the curve of ROC curve for PPSA and PSA as methods used to estimate prostate volume by prostate volume cutoff points (A) $<30 \mathrm{~mL}$, (B) $30-40 \mathrm{~mL}$, and (C) $>50 \mathrm{~mL}$. AUC, area under the curve.

cost-effective and routine evaluation of patients with BPH. Additionally, DRE is simple to perform and practical for estimating the PV, but it has been revealed that DRE underestimates the real prostate size [9].

In 1986, PSA testing was approved for the monitoring of men with prostate cancer (PCa), and was recognized as a cancer detection test in 1994 by the U.S. Food and Drug Administration. In spite of its low specificity, PSA is the most widely used screening test for PCa and is helpful for prediction of those men with $\mathrm{BPH}$ at risk for disease progression and therapeutic decisions [10].

Several independent investigators verified the log-linear relationship between serum PSA and PV in different population and races with similar results [11].

It was shown in a large sample of men with $\mathrm{BPH}$ that the total PSA level predicted the PV with an AUC ROC of 0.76 for a $\mathrm{PV}>40 \mathrm{~mL}$, with age-specific cutpoints of PSA level $>1.6,>2$, and $>2.3 \mathrm{ng} / \mathrm{mL}$ for men in their 50s, 60s, and 70s, respectively [12]. Bohnen et al. [13] showed that total PSA was a more accurate predictor of PV than digital rectal examination, with an AUC ROC of 0.86 for PV $>40 \mathrm{~mL}$. It was also shown that the AUC ROC for PSA for the differentiation of PVs $>50$ or $>30$, $>40$, and $>50 \mathrm{~mL}$ was $0.79,0.86$, and 0.92 .

There were continuous efforts to improve the diagnostic tools for the detection of PCa. The most promising approach to improve the specificity of PSA, particularly in the range lower than $10 \mathrm{ng} / \mathrm{mL}$, is the measurement of molecular isoforms of PSA. These are the disengaged PPSA and the complexed PSA bound to a1-antichymotrypsin. Several studies have shown an increase in sensitivities and specificities, primarily in the PSA range of lower $10 \mathrm{ng} / \mathrm{mL}$, for the ratio of free to total PSA (f/tPSA). They affirm that f/tPSA can better distinguish between patients with $\mathrm{PCa}$ and patients with a benign hyperplasia of the prostate $[14,15]$.

Previous reports have focused on the relationship between total PSA and PV in general. Although there have been some studies investigating the relationship between TPSA and PV in patients with $\mathrm{BPH}$, the relationship between $\mathrm{PPSA}$ and PV has received little attention. According to previous report on free and total PSA, there were strong relationship with PV, and they found that both laboratory tools would be able to predict the PV and the efficacy of total and free PSA showed no differences [16]. Other study on free PSA showed a log-linear relationship with PV and free PSA predicted PV more precisely than PSA in BPH patients [17].

The Chinese study on 286 biopsy proven BPH patients, among relationships between $\mathrm{PPSA}$, fPSA, age, and PV, the correlation between PPSA and PV was much stronger than that of PPSA and PV. The ROC curves revealed that the efficacy of fPSA at predicting threshold prostate sizes $(30,40$, and $50 \mathrm{~mL}$ ) showed AUC ranging from 0.72 to 0.75 , denoting better discrimination of PV than that of tPSA [18].

Since PPSA is more dependent on the benign prostate tissue volume than TPSA, we assumed that it may be less affected by PCa in which serum PSA elevation occurs as a result of destroyed normal prostatic structure. In other words, the more increase in fPSA may result from a larger prostate, and the more cancer contributes to a greater increase in TPSA than fPSA.

We confirmed that both tPSA and PPSA statistically correlated with PV. The ROC curves for PV $>30,>40$, and $>50 \mathrm{~mL}$ 
showed that AUC of fPSA are 0.781, 0.718, and 0.700. These are more efficient than that of tPSA: AUC $=0.657,0.583$, and 0.67 .

To the best of our knowledge, this study is the first to examine the relationship between PSA and PV in Korean men, and to show the efficacy of free PSA at predicting more precise PV in Korean men. Because of the ability to obtain more accurate estimates of the PV without the help of more expensive, invasive diagnostic evaluations, fPSA would introduce a more reasonable contribution in the proper management of patients with $\mathrm{BPH}$.

In conclusion, although tPSA significantly correlated with PV in Korean men with biopsy-proven BPH, the correlation between fPSA and PV was much stronger, and fPSA performed significantly better than tPSA at predicting thresholds of PV. fPSA may be used to estimate PV and could be a useful tool in making therapeutic decisions and longitudinal follow-up in Korean men with BPH.

\section{CONFLICT OF INTEREST}

No potential conflict of interest relevant to this article was reported.

\section{ACKNOWLEDGEMENTS}

This work was supported by the National Research Foundation of Korea (NRF) grant funded by the Korea government (MEST) (No. 2011-0020128).

\section{REFERENCES}

1. Madersbacher S, Alivizatos G, Nordling J, Sanz CR, Emberton M, de la Rosette JJ. EAU 2004 guidelines on assessment, therapy and follow-up of men with lower urinary tract symptoms suggestive of benign prostatic obstruction (BPH guidelines). Eur Urol 2004;46: 547-54.

2. Stenman UH, Leinonen J, Alfthan H, Rannikko S, Tuhkanen K, Alfthan O. A complex between prostate-specific antigen and alpha 1-antichymotrypsin is the major form of prostate-specific antigen in serum of patients with prostatic cancer: assay of the complex improves clinical sensitivity for cancer. Cancer Res 1991;51:222-6.

3. Lilja H, Christensson A, Dahlen U, Matikainen MT, Nilsson O, Pettersson $\mathrm{K}$, et al. Prostate-specific antigen in serum occurs predominantly in complex with alpha 1-antichymotrypsin. Clin Chem 1991;37:1618-25.

4. Hong SJ, Ko WJ, Kim SI, Chung BH. Identification of baseline clin- ical factors which predict medical treatment failure of benign prostatic hyperplasia: an observational cohort study. Eur Urol 2003;44: 94-9.

5. McConnell JD, Roehrborn CG, Bautista OM, Andriole GL Jr, Dixon CM, Kusek JW, et al. The long-term effect of doxazosin, finasteride, and combination therapy on the clinical progression of benign prostatic hyperplasia. N Engl J Med 2003;349:2387-98.

6. Jacobsen SJ, Jacobson DJ, Girman CJ, Roberts RO, Rhodes T, Guess HA, et al. Natural history of prostatism: risk factors for acute urinary retention. J Urol 1997;158:481-7.

7. Roehrborn CG, McConnell JD, Lieber M, Kaplan S, Geller J, Malek $\mathrm{GH}$, et al. Serum prostate-specific antigen concentration is a powerful predictor of acute urinary retention and need for surgery in men with clinical benign prostatic hyperplasia. PLESS Study Group. Urology 1999;53:473-80.

8. Torp-Pedersen S, Juul N, Jakobsen H. Transrectal prostatic ultrasonography: equipment, normal findings, benign hyperplasia and cancer. Scand J Urol Nephrol Suppl 1988;107:19-25.

9. Roehrborn CG, Girman CJ, Rhodes T, Hanson KA, Collins GN, Sech SM, et al. Correlation between prostate size estimated by digital rectal examination and measured by transrectal ultrasound. Urology 1997;49:548-57.

10. Smith DS, Catalona WJ, Herschman JD. Longitudinal screening for prostate cancer with prostate-specific antigen. JAMA 1996;276: 1309-15.

11. Boyle P, Gould AL, Roehrborn CG. Prostate volume predicts outcome of treatment of benign prostatic hyperplasia with finasteride: meta-analysis of randomized clinical trials. Urology 1996;48:398405.

12. Roehrborn CG, Boyle P, Gould AL, Waldstreicher J. Serum prostate-specific antigen as a predictor of prostate volume in men with benign prostatic hyperplasia. Urology 1999;53:581-9.

13. Bohnen AM, Groeneveld FP, Bosch JL. Serum prostate-specific antigen as a predictor of prostate volume in the community: the Krimpen study. Eur Urol 2007;51:1645-52.

14. Parsons JK, Brawer MK, Cheli CD, Partin AW, Djavan R. Complexed prostate specific antigen (PSA) reduces unnecessary prostate biopsies in the 2.6-4.0 ng/mL range of total PSA. BJU Int 2004;94:47-50.

15. Parsons JK, Partin AW. Applying complexed prostate-specific antigen to clinical practice. Urology 2004;63:815-8.

16. Morote J, Encabo G, Lopez M, de Torres IM. Prediction of prostate volume based on total and free serum prostate-specific antigen: is it reliable? Eur Urol 2000;38:91-5

17. Canto EI, Singh H, Shariat SF, Lamb DJ, Mikolajczyk SD, Linton $\mathrm{HJ}$, et al. Serum BPSA outperforms both total PSA and free PSA as 
a predictor of prostatic enlargement in men without prostate cancer. Urology 2004;63:905-10.

18. Mao Q, Zheng X, Jia X, Wang Y, Qin J, Yang K, et al. Relationships between total/free prostate-specific antigen and prostate volume in Chinese men with biopsy-proven benign prostatic hyperplasia. Int Urol Nephrol 2009;41:761-6. 